\title{
EVALUASI KINERJA AKUNTAN PUBLIK: SKEPTISME PROFESIONAL DAN OUTCOME EFFECT (SEBUAH STUDI EKSPERIMENTAL)
}

\author{
Gisilowati Dian Purnama Sari \\ Agung Juliarto \\ Raharja \\ Fakultas Ekonomika dan Bisnis Universitas Diponegoro
}

\begin{abstract}
Professional skepticism is a behavior that it is although encouraged by the profession does not always produce the same outcome (e.g., sometimes it leads to the identification of a misstatement and other times it may not). Highly skeptical auditors increase the likelihood that material misstatements are detected, which is important in promoting investor confidence and global financial stability. However, exercising skepticism may also come at a cost (e.g., budget overruns and potential conflicts with management). The failure to identify a material misstatement in the financial statements may result in restatements. Research on outcome effects suggests that auditor's performance evaluation may be influenced more by the outcome of their skeptical behavior (i.e., whether or not a misstatement is found) than by whether they engaged in the appropriate level of skeptical behavior. This study aims to obtain new empirical evidence whether there is a difference between the auditor's performance evaluation when a misstatement is found than when no misstatement is found. These studies further examine whether consultation during the process of exercising skepticism can alleviate the outcome effect bias. This is a experimental that research for a causal relationship between the dependent variabel and independent variable. Respondents in this study is the auditor who has experience doing supervision. Repondents were gethered in the seminar organized by IAPI and PPPK. Seminar was held on 2016 may 30 ${ }^{\text {th }}$, in Semarang Quest Hotel. Testing of this reserch using indepent sample t-test and two way ANOVA. Finding of first experiment finds that the outcome of an investigation will affect auditors' performance evaluations. There are significant differences of performance evaluations between staff who do not identify a misstatement versus staff who do identify a misstatement. This reserach also examine whether responses are significantly higher when a misstatement is found than when no misstatement is found. Futhermor result of this study reveal that consultation with the superior during the process of exercising skepticism effectively mitigate the outcome effects in auditor evaluations. The result of this study show that the evaluators did not effected the outcome effect in auditor's performance evaluation.
\end{abstract}

Keywords : Professional Skepticism, outcome effect, Auditor's Performance Evaluation

PENDAHULUAN

Evaluasi kinerja dapat dikatakan sebagai salah satu proses yang paling penting dalam profesi akuntan publik.

Auditor sering dievaluasi pada setiap penugasan audit, dan evaluasi tersebut 
menjadi masukan utama dalam evaluasi berkala yang dilakukan untuk tujuan promosi dan kenaikan gaji (Wright, 1980; Hunt, 1995). Evaluasi kinerja dapat membantu dalam kontrol kualitas dan dapat mengarahkan karyawan menuju perilaku pekerjaan yang diinginkan (Hunt, 1995). Evaluasi kinerja juga memainkan peran penting dalam pengendalian mutu auditor.

Evaluasi kinerja dapat dipahami dalam kerangka yang mencakup dampak kognitif mental accounting dan framing. Mental accounting berfokus pada bagaimana seyogianya keputusan seseorang menyikapi dan mengevaluasi suatu situasi saat terdapat dua atau lebih kemungkinan hasil, khususnya bagaimana mengkombinasikan kemungkinan-kemungkinan hasil tersebut (Thaler, 2008). Jones dan Chen (2005) meneliti dampak framing pada persepsi evaluator. Framing adalah sebuah fenomena yang mengindikasikan pengambil keputusan akan memberikan respon dengan cara yang berbeda pada masalah yang sama jika disajikan dalam format yang berbeda (Tversky dan Kahneman, 1986). Penelitian mental accounting mengasumsikan, biaya investigasi yang menghasilkan manfaat dibingkai sebagai biaya (frame as cost), sedangkan biaya investigasi yang tidak menghasilkan manfaat dibingkai sebagai (frame as loss). Pihak yang melakukan evaluasi biasanya akan memberikan penilaian kinerja lebih tinggi jika biaya investigasi dianggap sebagai cost frame (Lipe, 1993).

Fokus utama evaluasi kinerja manajer adalah efisiensi, yang dapat berpotensi merusak skeptisme profesional (Tan dan Libby, 1997). Pada lingkungan ekonomi saat ini, perusahaan menghadapi tekanan yang meningkat untuk mengurangi biaya, termasuk biaya untuk membayar Kantor Akuntan Publik (KAP). Pengungkapan fee audit ke publik juga telah menciptakan tekanan pada biaya audit di industri (Reason, 2010). Kecenderungan penurunan dalam biaya audit pada gilirannya dapat memberikan tekanan pada KAP untuk memotong biaya atau meningkatkan efisiensi audit dalam rangka untuk memaksimalkan keuntungan.

Skeptisme profesional adalah produk judgment auditor, namun skeptisme profesional dapat diungkapkan oleh perilaku skeptis, karena hal tersebut adalah atribut kinerja auditor (Nelson, 2009). Nilai dari proses evaluasi untuk meningkatkan skeptisme profesional tergantung pada keakuratan evaluasi kinerja. Pertanyaan yang menarik adalah sejauh mana proses penilaian kinerja dan promosi secara 
eksplisit maupun implisit menilai dan memberikan penghargaan terhadap skeptisme profesional.

Penelitian terdahulu diantaranya Tan dan Lipe (1997), Jones dan Chen (2005) yang berkaitan dengan evaluasi kinerja yaitu evaluasi kinerja auditor mungkin akan lebih dipengaruhi oleh outcome dari perilaku skeptis mereka. Outcome dari perilaku skeptis ini adalah apakah ada atau tidak ada salah saji ditemukan. Sedangkan evaluasi auditor tidak dipertimbangkan dari apakah mereka terlibat dalam tingkat yang tepat dari perilaku skeptis yaitu tepat mengidentifikasi dan menyelidiki red flag atau inkonsistensi. Seperti penelitian Jones dan Chen (2005) menunjukan kekokohan teori tentang outcome effect dalam konteks mengevaluasi kinerja pada perikatan audit. Penelitian tersebut memberikan bukti bahwa evaluator memiliki "frame" yang berbeda-beda tergantung pada outcome, sehingga mempengaruhi evaluasi kinerja. Outcome effect mengacu pada fenomena dimana evaluator mendasarkan evaluasi kinerja berdasarkan outcome dari keputusan tersebut, tanpa mengetahui bagaimana pengambilan keputusan itu dipilih (Tan dan Lipe, 1997). Auditor dianggap berprestasi jika menemukan salah saji, tidak seperti yang diharapkan oleh Mertins et al (2013) yaitu kriteria yang tepat untuk mengevaluasi auditor adalah berdasarkan dari bukti yang mereka temukan.

Penelitian terdahulu menyebutkan bahwa budaya konsultasi diharapkan dapat mengurangi outcome effect. Glover et al. (2014) menunjukkan bahwa menciptakan budaya konsultasi dapat meningkatkan aplikasi yang sesuai skeptisme. Hasil penelitian Mertins (2013) menyebutkan bahwa outcome effect berkurang (meski tidak dihilangkan) ketika evaluator mengamati proses pengambilan keputusan. Demikian juga Tan dan Lipe (1997) menyebutkan konsultasi dengan atasan mungkin juga mengurangi outcome effect dengan mengurangi asimetri informasi. Namun, sebaliknya penelitian Brazel (2015) menyebutkan bahwa konsultasi dengan atasan tidak mengurangi outcome effect dalam evaluasi auditors.

Hal ini menjadi menarik untuk diteliti karena yang pertama adalah apakah memang informasi "outcome" (yaitu, apakah ada atau tidak ada salah saji yang diidentifikasi) dalam skeptisme profesional auditor untuk melakukan investigasi mempengaruhi evaluasi kinerja. Kedua adalah apakah konsultasi memang dapat mengurangi outcome effect atau tidak. Selain itu menarik juga untuk diteliti karena banyak studi 
merujuk pada outcome bias yang fokusnya pada outcome, bukan pada ketidakpastian yang melekat dalam keputusan pada saat keputusan itu dibuat (misalnya, Baron dan Hershey 1988; Ghosh dan Lusch 2000).

Penelitian ini unik karena mendeteksi salah saji dari inkonsistensi antara akun pendapatan dan informasi non keuangan (Non Financial Measure /NFM). Non Financial Measure merupakan salah satu informasi relevan yang dapat dijadikan pertimbangan auditor dalam menaksir risiko ketika melakukan tahap awal pada perencanaan pengujian substantif. Public Company Accounting Oversight Board (PCAOB) menyebutkan bahwa potensi NFM dapat dijadikan patokan independen untuk mengevaluasi validitas data laporan keuangan. PCAOB juga mengesahkan penggunaan NFM untuk meningkatkan deteksi fraud (PCAOB;2007). Selain itu, Bell et al. (2005) menyatakan bahwa Non Financial Measures (NFM) kurang rentan terhadap manipulasi data dan lebih mudah diverifikasi kepada pihak yang membuatnya. Beberapa faktor menunjukkan bahwa NFM sulit untuk dimanipulasi, atau setidaknya jika manipulasi dilakukan maka sulit untuk disembunyikan. Selain itu beberapa penelitian menyebutkan bahwa adanya inkonsistensi informasi non keuangan dan keuangan terjadi pada perusahaan yang terbukti telah melakukan kecurangan seperti penelitian seperti Brazel et al. (2009) dan Dechow et al. (2011).

Informasi non finansial tersebut diantaranya adalah jumlah karyawan, jumlah pelanggan, kuantitas produksi dan variasi produk. Materi eksperimen dalam penelitian ini didasarkan pada hasil penelitian Brazel et al. (2009) yang mengidentifikasi bahwa inkonsistensi antara ukuran finansial dan nonfinancial measures (NFM) sebagai red flag. Survei oleh Brazel et al. (2014) dari audit patner dan manajer menemukan bahwa peringkat red flag NFM menjadi risiko kecurangan tertinggi daripada beberapa red flag umum lainnya (misalnya: perputaran Chief Financial Officer tahun berjalan dan manajemen yang enggan merekam setiap penyesuaian audit). Penelitian model ini mengacu pada penelitian yang dilakukan oleh Brazel et al (2015).

\section{KERANGKA TEORITIS DAN PENGEMBANGAN HIPOTESIS}

Pengaruh Skeptisme Profesional Auditor Junior terhadap Evaluasi Kinerja oleh Auditor Senior

Standar profesional akuntan publik mendefinisikan skeptisme profesional sebagai sikap auditor yang mencakup 
pikiran yang selalu mempertanyakan dan melakukan evaluasi secara kritis terhadap bukti audit. Definisi tersebut dinyatakan dalam Standar Perikatan Audit (SPA) No. 200. Penelitian Nelson (2009) dan Hurtt et al (2013) menyebutkan skeptisme profesional auditor terdiri dari dua komponen utama: skeptical judgment (identifikasi masalah) dan skeptical action (penyelidikan tambahan). Skeptisme profesional merupakan produk judgment auditor, namun skeptisme profesional dapat diungkapkan melalui perilaku skeptis, karena hal tersebut adalah atribut kinerja auditor (Nelson, 2009). Penelitian Beasley et al. (2001) dalam Noviyanti (2015) menyatakan bahwa salah satu penyebab kegagalan auditor dalam mendeteksi kecurangan adalah rendahnya tingkat skeptisme profesional audit. Kegagalan audit terjadi ketika auditor mengeluarkan pendapat wajar tanpa pengecualian atas laporan keuangan yang kemudian terbukti ditemukan kecurangan atau salah saji material. Auditor yang memberikan opini tidak benar akan dinilai kurang skeptis. Artinya bahwa, kinerja auditor terkadang dinilai dari skeptisme profesional berdasarkan dari outcome yaitu dari temuan salah saji material.
Skeptisme profesional membutuhkan usaha tambahan dari auditor dan klien, akan tetapi tidak menjamin bahwa salah saji akan ditemukan. Ada kemungkinan bahwa penyelidikan mengarah ke penjelasan yang dapat diterima untuk pola yang tidak biasa dari fakta-fakta yang diamati, sehingga tidak ada penyesuaian audit yang diperlukan. Penelitian Nelson (2009) menyebutkan skeptisme profesional yang tinggi mungkin tidak akan mengasilkan audit yang memiliki keseimbangan optimal antara efektifitas dan efisiensi. Auditor yang terlalu skeptis dan audit yang skeptisme profesional sangat tinggi mungkin tidak efisien.

Nilai dari proses evaluasi untuk meningkatkan skeptisme profesional tergantung pada keakuratan evaluasi kinerja, fokus utama evaluasi kinerja manajer adalah efisiensi. Hal ini dapat berpotensi merusak skeptisme profesional ( Tan dan Libby, 1997). Shaub dan Lawrence (2002) berpendapat bahwa sikap skeptis yang diukur jauh lebih baik, karena sikap tersebut akan mengambil tindakan bila diperlukan tetapi tidak berlebihan skeptis yang menimbulkan audit menjadi tidak efisien. Penelitian Brazel (2015) menyebutkan bahwa evaluator yaitu partner dan manajer KAP memberikan hukuman kepada auditor yang menggunakan skeptisme profesional 
pada tingkat yang tepat, tetapi tidak mengidentifikasi salah saji. Skeptisme profesional melibatkan tingkat kepercayaan yang disertai dengan verifikasi yang tepat. Sehingga penerapan skeptisme profesional dapat membantu auditor untuk mencapai keseimbangan yang optimal efektivitas dan efisiensi (Glover, 2014). Evaluator akan memandang skeptisme profesional auditor yang menemukan salah saji lebih skeptis dibandingkan yang tidak menemukan salah saji. Temuan audit dapat dilihat sebagai sebuah peningkatan efektivitas audit (Jones dan Chen, 2005).

Auditor skeptis dapat menurunkan risiko perusahaan dengan mengurangi risiko bahwa salah saji material akan terdeteksi, namun skeptisme auditor dapat menyebabkan pertanyaan atau prosedur tambahan dan anggaran yang berlebih. Untuk memahami bagaimana outcome dalam evaluasi auditor diperlukan pertimbangan biaya yang berkaitan dengan tindakan skeptis. Biaya tersebut terkait dengan sumberdaya tambahan yang dipergunakan untuk melakukan prosedur tambahan. Sehingga ketika biaya dikeluarkan akan tetapi kemudian tidak menemukan salah saji menjadi tampak kurang menarik.
Evaluator atau seorang pengambil keputusan akan mengambil keputusannya secara tidak sengaja mengarah pada salah satu bentuk framing (Kahneman dan Tversky, 1979). Evaluator memiliki pandangan asas biaya dan manfaat yaitu bahwa skeptisme profesional yang menemukan salah saji akan lebih menguntungkan daripada skeptisme yang tidak menemukan salah saji. Singkatnya, bahwa biaya yang dikeluarkan untuk menjadi skeptis telah menerima manfaat dengan menemukan salah saji (cost frame), dan sebaliknya biaya untuk menjadi skeptis tidak menerima manfaat ketika tidak menemukan salah saji (loss frame). Sehingga auditor skeptis yang menemukan salah saji akan dievaluasi kinerjanya oleh evaluator, jauh lebih baik daripada auditor skeptis yang tidak menemukan salah saji. Lipe (1993) proses evaluasi kinerja pada umumnya akan dievaluasi lebih efektif jika menemukan salah saji. Jones dan Chen (2005) juga mengemukakan hal yang sama bahwa dalam konteks audit yang over budget, evaluator akan menilai kinerja auditor jauh lebih baik ketika mendapatkan temuan yang signifikan. Berdasarkan hal tersebut sehingga dapat dirumuskan hipotesis pertama sebagai berikut: 
$\mathbf{H}_{1}$ : Atasan auditor dengan persepsi bahwa bawahannya bersikap skeptis akan menilai kinerja auditor lebih tinggi ketika menemukan salah saji daripada tidak menemukan salah saji.

\section{Pengaruh Hasil Temuan Auditor Junior dan Konsultasi terhadap Evaluasi Kinerja oleh Auditor Senior}

Evaluasi yang terlalu dipengaruhi oleh informasi outcome dapat merugikan bagi organisasi karena auditor akan fokus pada menemukan salah saji bukan untuk meningkatkan skeptsime profesional. Hal ini sesuai dengan yang dikemukakan oleh Mertins (2013) yaitu bahwa kriteria yang tepat untuk mengevaluasi auditor berprestasi bukan dari temuan salah saji, tetapi berdasarkan bukti yang auditor temukan. Evaluasi kinerja auditor mungkin akan lebih dipengaruhi oleh outcome dari perilaku skeptis (yaitu apakah ada atau tidak ada salah saji ditemukan) daripada apakah auditor terlibat dalam tingkat yang tepat dari perilaku skeptis. Hal ini disebut sebagai outcome effect, yaitu sebuah fenomena dimana evaluator dalam hal mendasarkan evaluasi kinerja berdasarkan outcome dari keputusan tersebut, tanpa mengetahui bagaimana pengambilan keputusan itu dipilih (Tan dan Lipe, 1997).
Sebagian besar outcome effect masih ada dalam penelitian akuntansi yang telah dilakukan dalam bidang evaluasi kinerja, seperti dalam penelitian penganggaran modal (Brown dan Solomon 1987, 1993), analisis keuangan (Fisher dan Selling 1993), pengambilan keputusan bisnis strategis (Tan dan Lipe 1997), keputusan investigasi (Lipe 1993), perpajakan (Kadous and Magro 2001), and evaluasi kinerja (Frederickson, Peffer and Pratt 1999). Literatur akuntansi menunjukkan bahwa sumber utama dari outcome effect berasal dari rekonstruksi kognitif yang terjadi selama proses evaluasi (misalnya, Brown dan Salomo 1993).

Salah satu cara untuk mengurangi outcome effect adalah dengan budaya konsultasi. Disebutkan oleh Brown dan Solomon (1993) yaitu konsultasi dengan atasan mungkin juga mengurangi outcome effect dengan mengurangi asimetri informasi. Glover et al. (2014) menunjukkan juga bahwa menciptakan budaya konsultasi dapat meningkatkan aplikasi yang sesuai skeptisme. Jika atasan auditor (evaluator) terlibat dalam keputusan yang diambil oleh auditor junior maka proses pengambilan keputusan diamati, jika diamati maka akan mudah diukur. Pengaruh keterlibatan atasan dalam skeptisme profesional juga disebutkan oleh Noviyanti (2015) yaitu bahwa sikap 
skeptisme profesional auditor dapat ditingkatkan jika dimotivasi oleh "high tone" dari gaya kepemimpinan patner. Penelitian Carpenter (2013) juga menyebutkan bahwa efek penekanan partner (partner emphasis) yang dipimpin oleh pasangan yang menekankan skeptisme profesional dan efektifitas adalah lebih efektif dan efisien dalam investigasi kecurangan. Nelson (2009) menyebutkan bahwa sesi brainstorming kecurangan merupakan salah satu pengaturan konsultasi yang dapat meningkatkan skeptisme profesional. Ada kemungkinan berdasarkan hasil penelitian tersebut bahwa efek partner emphasis dan gaya kepemimpinan yang "high tone" yang menekankan pada skeptisme profesional, akan memandang perilaku skeptis bawahan tidak hanya berdasarkan hasil temuan audit saja, tetapi lebih menilai sikap skeptisme profesional yang dimiliki bawahannya.

Studi di bidang akuntansi menyebutkan bahwa evaluator akan menilai lebih keras ketika mereka diberi informasi tentang informasi outcome yang negatif atau merugikan (misalnya, Kadous, 2001; Clarkson, Emby dan Watt, 2002). Evaluator (auditor senior) yang terkena outcome effect akan menilai kinerja evaluatee (auditor junior) berdasarkan outcome yaitu berdasarkan ada atau tidak temuan salah saji, tanpa mempertimbangkan apakah auditor junior cukup skeptis dalam tindakannya. Skeptisme profesional didasarkan pada hasil temuan auditor. Auditor yang tidak menemukan salah saji akan dipandang memiliki kinerja kurang baik atau kurang skeptis daripada auditor yang menemukan salah saji. Padahal dengan adanya konsultasi sesuai dengan teori eskalasi komitmen (Staw, 1976), atasan akan memiliki motivasi untuk memandang perilaku skeptis lebih menguntungkan (Brown dan Salomon, 1993). Konsultasi diharapkan akan mengurangi outcome effect pada keputusan evaluator. Auditor yang tidak menemukan salah saji tidak akan selalu dinilai kurang skeptis, dan sebaliknya auditor yang menemukan salah saji tidak akan akan selalu dinilai lebih skeptis. Oleh karena itu dapat dirumuskan hipotesis kedua adalah sebagai berikut:

$\mathbf{H}_{2}$ : Atasan Auditor yang tidak terkena outcome effect akan menilai kinerja auditor yang melakukan konsultasi, berbeda secara signifikan dengan kinerja auditor yang tidak melakukan konsultasi.

\section{METODE PENELITIAN}

\section{Subyek Penelitian}

Pertisipan yang dilibatkan dalam eksperimen penenelitian ini adalah 61 
auditor yang bekerja di KAP. Partisipan auditor dikumpulkan dalam sebuah acara seminar yang diselengarakan oleh IAPI dan PPPK pada tanggal 30 Mei 2016 di Quest Hotel Semarang. Pertimbangan dalam memilih subyek tersebut adalah untuk dapat mewakili proksi pengambilan keputusan yang sebenarnya. Hal ini dikarenakan partisipan teleh bekerja sebagai auditor dan berpengalaman dalam pengambilan keputusan audit.

Partisipan dikelompokan dalam empat kondisi perlakuan, masing-masing pertisipan mendapatkan satu kondisi treatment. Partisipan bertindak sebagai auditor senior yang bertugas melakukan evaluasi kinerja auditor junior. Pemberian tugas eksperimen dilakukan secara acak (randomly assigned) atas dua kondisi perlakuan yaitu auditor junior menemukan salah saji dan tidak menemukan salah saji dan dengan konsultasi dan tidak konsultasi. Penempatan acak (random assignment) ke dalam kelompok- kelompok diperlukan untuk membuat kelompok-kelompok itu dapat dibandingkan dengan variabel dependen (Cooper dan Schindler, 2001). Sekaran (2000) juga mengemukakan bahwa proses randomisasi akan menjamin masing-masing kelompok dalam comparable satu sama lain.

\section{Desain Penelitian}

Penelitian ini menggunakan desain eksperimen untuk menginvestigasi hipotesis-hipotesis dengan factorial design 2 x 2 dengan between-subject. Eksperimen dimanipulasi dengan kondisi auditor junior menemukan salah saji dan tidak menemukan salah saji dan dengan konsultasi dan tidak konsultasi. Pertisipan bertindak sebagai evaluator yang menilai kinerja auditor junior dalam pengambilan keputusan. Partisipan hanya menerima salah satu dari empat kondisi yang ada. Tabel 1 menunjukkan desain eksperimen.

Tabel 1

Desain Eksperimen Pertama 2 x 2 ( Skeptisme Auditor x Skor)

\begin{tabular}{lcc}
\hline & \multicolumn{2}{c}{ Skor Nilai } \\
\cline { 2 - 3 } Skeptisme Auditor & Tinggi & Rendah \\
\hline Salah Saji & A1 & A2 \\
Tidak Salah Saji & C1 & C2 \\
\hline
\end{tabular}


Eksperimen pertama, partisipan diberikan untuk mengevaluasi kinerja auditor junior sesuai dengan kondisi perlakuan, pada masing-masing jenis treatment tersebut adalah : (1) kondisi auditor junior menemukan salah saji dan dievaluasi dengan skor tinggi (Sel A1), kondisi auditor junior menemukan salah saji dan dievaluasi dengan skor rendah (Sel A2), auditor junior tidak menemukan salah saji dan dievaluasi dengan skor tinggi (Sel B1), auditor junior tidak menemukan salah saji dan dievaluasi dengan skor rendah (Sel B2).

Tabel 2

Desain Eksperimen Kedua 2 x 2 ( Skeptisme Auditor x Judgment Auditor)

\begin{tabular}{ccc}
\hline & \multicolumn{2}{c}{ Judgment Auditor } \\
\cline { 2 - 3 } Skeptisme Auditor & Konsultasi & Tidak Konsultasi \\
\hline Salah Saji & A & B \\
Tidak Salah Saji & C & D \\
\hline
\end{tabular}

Eksperimen kedua, partisipan diberikan untuk mengevaluasi kinerja auditor junior sesuai dengan kondisi perlakuan, pada masing-masing jenis treatment tersebut adalah : (1) kondisi auditor junior menemukan salah saji dan melakukan konsultasi degan auditor senior (Sel A), kondisi auditor junior menemukan salah saji dan tidak melakukan konsultasi degan auditor senior (Sel B), kondisi auditor junior tidak menemukan salah saji dan melakukan konsultasi degan auditor senior (Sel C), kondisi auditor junior tidak menemukan salah saji dan tidak melakukan konsultasi degan auditor senior (Sel D).

\section{Varibael Independen}

Variabel independen adalah variabel yang menjelaskan atau mempengaruhi variabel yang lain. Variabel independen dalam hipotesis 1 dan 2 yang dimanipulasi dalam penelitian ini adalah skeptisme profesional. Apakah skeptisme profesional auditor yang menghasilkan informasi "outcome" (yaitu, apakah ada atau tidak ada salah saji yang diidentifikasi) mempengaruhi evaluasi keputusan auditor untuk melakukan investigasi. Outcome adalah hasil investigasi staff auditor, yang dimanipulasi diantara peserta sebagai (1) Staff auditor yang berperilaku skeptis menemukan bahwa ada salah saji (dikodekan sebagai 1) atau (2) 
Staff auditor yang berperilaku tidak skeptis tidak menemukan salah saji (dikodekan sebagai 0).

\section{Variabel Dependen}

Variabel dependen adalah tipe variabel yang dijelaskan atau dipengaruhi oleh variabel independen. Variabel dependen dalam penelitian ini adalah mengukur tanggapan dari responden ketika mengevaluasi kasus yang variabel independennya telah dimanupulasi. Kasus dalam penelitian menyediakan informasi bahwa staff auditor memutusakan untuk menyelidiki inkonsistensi antara akun pendapatan dan pengukuran non keuangan, yang merupakan manifestasi dari skeptisme profesional. Keputusan staff auditor untuk mengumpulkan dan mempertimbangkan alternatif bukti yang tidak konsisten, dapat dianggap sebagai perilaku skeptis. Dengan kata lain, jika staff auditor hanya mengulangi pengujian yang sama yang dilakukan pada tahun sebelumnya maka inkonsistensi tidak dapat diidentifikasi. Instrumen variabel dependen dalam penelitian ini mengacu pada penelitian Brazel et al (2015).

\section{Variabel Moderating}

Variabel moderating adalah variabel yang mempengaruhi (memperkuat/ memperlemah) hubungan antara variabel bebas dan variabel terikat. Variabel moderator disebut juga variabel independen kedua. Variabel moderating dalam penelitian ini adalah konsultasi. Evaluasi dianggap mampu mempengaruhi penilaian evaluator dan mengurangi outcome effect dalam penilaiannya (Brown dan Solomon 1993). Kondisi tidak ada konsultasi mencerminkan pilihan untuk hanya mengandalkan pada penilaian sendiri seseorang. Kondisi konsultasi mencerminkan pilihan untuk menginformasikan kepada atasan mereka tentang situasi dan mendapatkan persetujuan mereka sebelum menimbulkan biaya yang terkait dengan menyelidiki ketidakkonsistenan antara akun pendapatan dan pengukuran non finansial (misalnya: jumlah pelanggan, jumlah karyawan, kuantitas produksi, variasi produk). Instrumen variabel dependen dalam penelitian ini mengacu pada penelitian Brazel et al (2015).

\section{Materi Eksperimen}

Penelitian ini menggunakan instrumen yang dikembangkan oleh Brazel et al (2015) dan selanjutnya disesuaikan dengan kebutuhan penelitian di Indonesia. Kasus menempatkan peserta dalam posisi sebagai auditor senior yang mengevaluasi kinerja 
auditor junior pada perikata audit untuk perusahaan Madison. Auditor junior dalam kasus disebut dengan tokoh Sam. Sedangkan Madison adalah sebuah perusahaan go public dengan beberapa divisi dan Sam bertugas untuk mengaudit pada Divisi Sporting Good.

Peserta mendapatkan informasi bahwa Madison telah menjadi klien KAP dimana Sam bekerja selama 3 tahun dan telah menerima opini audit wajar tanpa pengecualian setiap tahun. Kasus eksperimen juga memberikan informasi tentang hubungan auditor dengan klien, yaitu: (1) Perusahaan Madison adalah klien besar di KAP, (2) Terdapat tekanan untuk menjaga biaya audit agar tidak melebihi anggaran, (3) Secara historis terdapat beberapa penyesuaian audit (4) Madison (klien) mengharapkan agar audit berjalan lancar dan klien meminta penjelasan ketika sifat, waktu dan luas prosedur berubah.

Peserta diberitahu bahwa tugas mereka adalah untuk mengevaluasi auditor junior yaitu Sam yang bekerja dibawah pengawasan mereka. Tanggungjawab Sam diantara tugas lainnya yaitu melakukan analisis pengujian substantif yang terkait dengan akun pendapatan Sporting Goods di Madison. Pada audit tahun lalu, prosedur analitis yang dilakukan telah memasukan informasi keuangan tahun sebelumnya dan tren keuangan. Jika Sam mencari konfirmasi atau bukti yang konsisten, maka Sam akan cenderung menggunakan sumber informasi yang sama seperti audit tahun sebelumnya.

\section{Eksperimen pertama, skeptisme} profesional dalam eksperimen adalah ketika Sam memasukan informasi non finansial/Nonfinancial Measures (NFM) seperti jumlah karyawan dan kuantitas produksi, yang tidak dipertimbangkan pada audit di tahun sebelumnya. Sam melihat melihat ketidakkonsistenan antara akun pendapatan dan NFM, dan kemudian memutuskan untuk menyelidiki inkonsistensi tersebut. Sikap Sam tersebut merupakan manifestasi dari skeptisme profesional. Disebutkan dalam literatur yang berkaitan dengan skeptisme profesional menekankan tentang pentingnya mengevaluasi bukti yang tidak konsisten (IAASB, 2004a). Dengan demikian, keputusan Sam untuk mengumpulkan dan mempertimbangkan alternatif bukti yang tidak konsisten, dapat dianggap sebagai perilaku skeptis.

Eksperimen kedua, apakah diperlukan pertimbangan atau tidak antara Sam dengan atasanya (peserta eksperimen) yaitu memutuskan untuk melakukan penyelidikan ketidakkonsistenan antara akun 
pendapatan dengan NFM dan, karena penyelidikan tersebut akan menjadi go over budget. Ringkasan Model Tugas Eksperimen dapat dilihat pada gambar 3.3 dan Gambar Kelompok Kasus Eksperiman eksperimen dapat dilihat pada 3.4. Skenario dalam penelitian ini dibagi dalam 4 kasus, yaitu :

\section{- Kasus A}

Sam melakukan penyelidikan ketidakkonsistenan antara akun pendapatan dan NFM (manifestasi sikap skeptis). Akan tetapi sebelum melakukan penyelidikan Sam melakukan konsultasi dengan atasannya yaitu untuk melakukan pemeriksaan lebih lanjut dan mengumpulkan bukti-bukti. Hasil dari penyelidikan tersebut adalah ada salah saji material dalam akun pendapatan.

- Kasus B

Sam melakukan penyelidikan ketidakkonsistenan antara akun pendapatan dan NFM (manifestasi sikap skeptis). Akan tetapi sebelum melakukan penyelidikan Sam tidak konsultasi dengan atasannya untuk melakukan pemeriksaan lebih lanjut dan mengumpulkan bukti-bukti. Hasil dari penyelidikan tersebut adalah ada salah saji material dalam akun pendapatan.

- Kasus C

Sam melakukan penyelidikan ketidakkonsistenan antara akun pendapatan dan NFM (manifestasi sikap skeptis). Akan tetapi sebelum melakukan penyelidikan Sam melakukan konsultasi dengan atasannya yaitu untuk melakukan pemeriksaan lebih lanjut dan mengumpulkan bukti-bukti. Hasil dari penyelidikan tersebut adalah adanya tidak ada salah saji material dalam akun pendapatan.

- Kasus D

Sam melakukan penyelidikan ketidakkonsistenan antara akun pendapatan dan NFM (manifestasi sikap skeptis). Akan tetapi sebelum melakukan penyelidikan Sam tidak konsultasi dengan atasannya untuk melakukan pemeriksaan lebih lanjut dan mengumpulkan bukti-bukti. Hasil dari penyelidikan tersebut adalah adanya tidak ada salah saji material dalam akun pendapatan. 


\section{Gambar 1}

\section{Ringkasan Model Tugas Eksperimen}

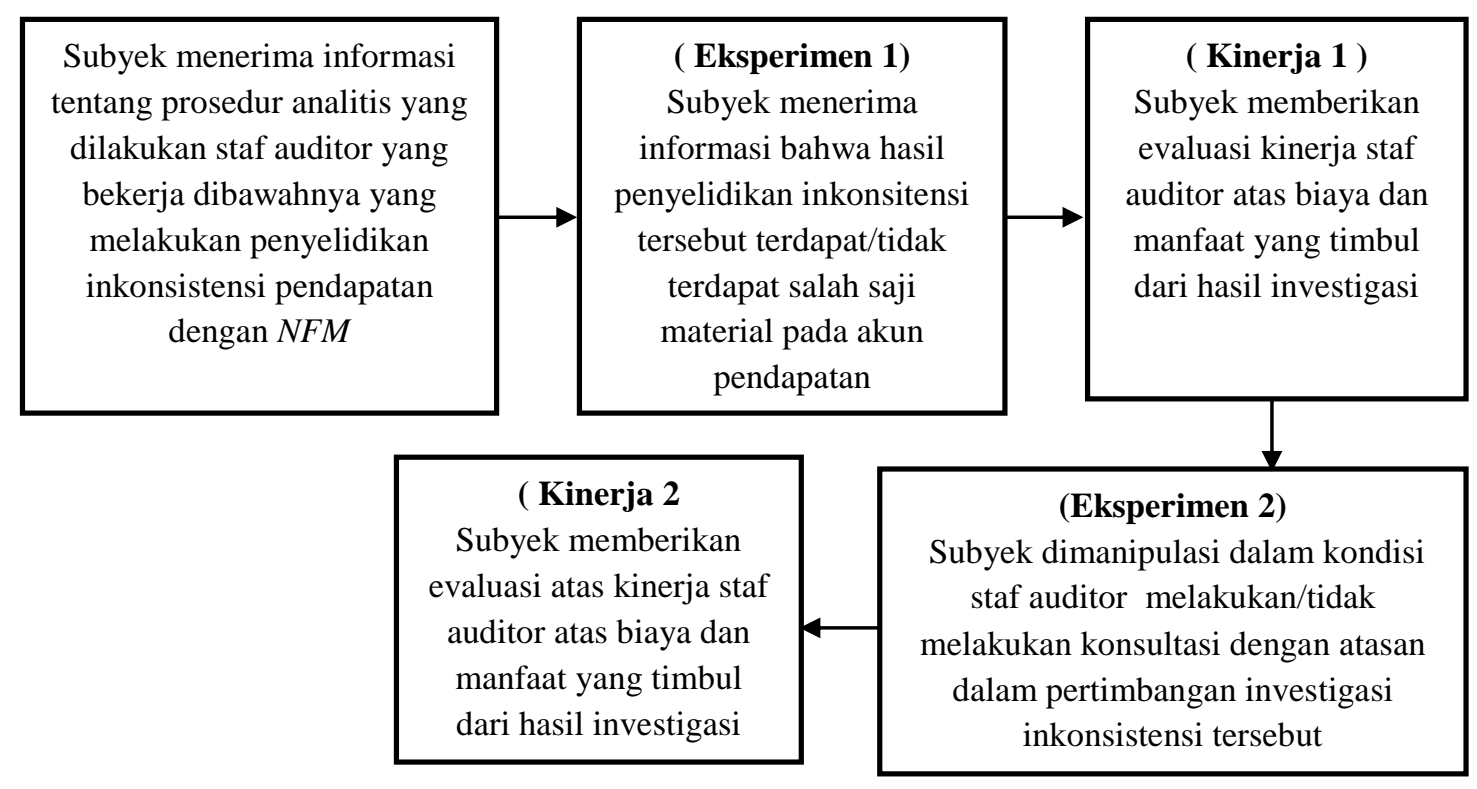

\section{Gambar 2}

\section{Kelompok Kasus Eksperimen}

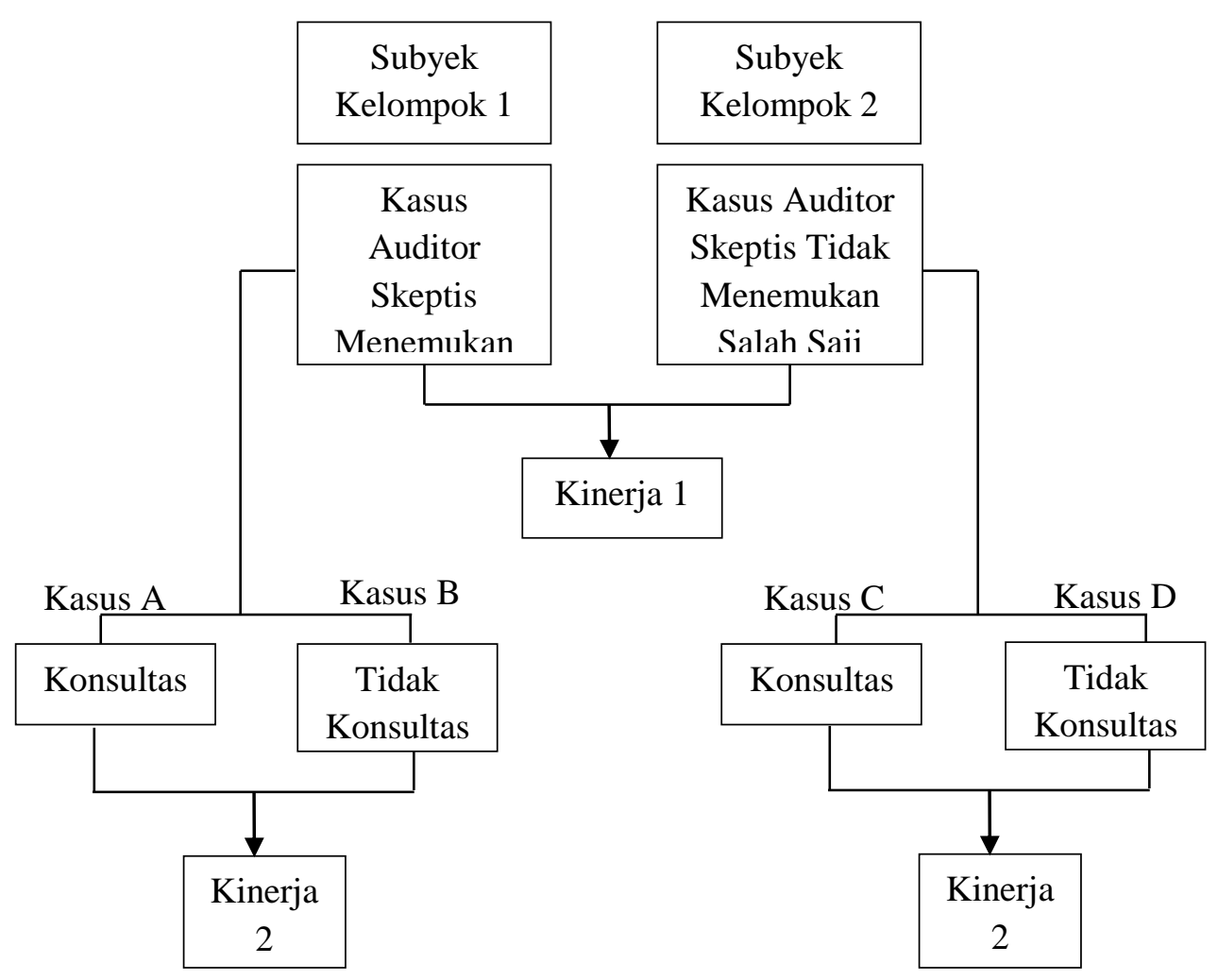




\section{Metode Analisi Data}

Teknik analisis statistik deskriptif digunakan untuk memberikan gambaran tentang demografi partisipan. Selain itu dilakukan pada uji anova yang menunjukkan bahwa keempat grup tersebut memiliki ratarata karakteristik yang identik. Pengujian normalitas data juga dilakukan untuk menentukan alat uji statistik yang tepat dalam menguji hipotesis.

Pengujian hipotesis 1 dan hipotesis 2 dilakukan dengan menggunakan ANOVA yaitu two way anova. Pengujian dengan ANOVA memungkinkan untuk mengetahui main effect (pengaruh utama) dari variabel independen skeptisme profesional dan terhadap variabel dependen evaluasi kinerja auditor (pengujian hipotesis 1) dan pengaruh utama variabel budaya konsultasi terhadap variabel dependen evaluasi kinerja auditor (pengujian hipotesis 2).

\section{HASIL PENELITIAN DAN PEMBAHASAN}

\section{Hasil Cek Manipulasi}

Penelitian ini menggunakan satu pertanyaan cek yang disajikan diakhir skenario. Pertanyaan tersebut digunakan sebagai indikator pemahaman pertisipasi terkait dengan manipulasi yang diberikan kepada pelapor pada kasus yang disajikan. Pada penelitian ini instrumen skeptisme profesional, pertanyaan cek manipulasi yaitu tentang apakah tokoh dalam skenario memiliki tingkat yang kurang atau lebih skeptis dalam melakukan keputusan investigasi.

Pada tahap pertanyaan diberikan dan pilihan jawaban. Partisipan yang menjawab pertanyaan cek dengan benar dianggap memahami kasus yang disajikan, sehingga data pertisipan tersebut layak digunakan dalam penelitian ini. sedangkan pertisipan yang gagal menjawab tes manipulasi maka data dari pertisipan tersebut tidak dapat digunakan dalam penelitian ini.

Hasil analisis cek manipulasi menunjukan bahwa dari total 64 partisipan, hanya sebanyak 61 partisipan yang lolos dan 3 partisipan gagal cek manipulasi. Kegagalan ini bisa disebabkan karena partisipan tidak menjawab soal dengan lengkap atau partisipan tidak memahami soal yang diberikan.

\section{Karakteristik Demografi}

Tabel 3 berikut ini menggambarkan karakteristik demografis partisipan yang mengikuti eksperimen beserta distribusinya berdasarkan kelompok manipulasi. Pengelompokan partisipan ke dalam kelompok manipulasi dilakukan secara acak 
(random assignment). Data partisipan yang yang lulus cek manipulasi.

ditunjukkan pada tabel 3ini hanya partisipan

Tabel 3

Karakteristik Demografi

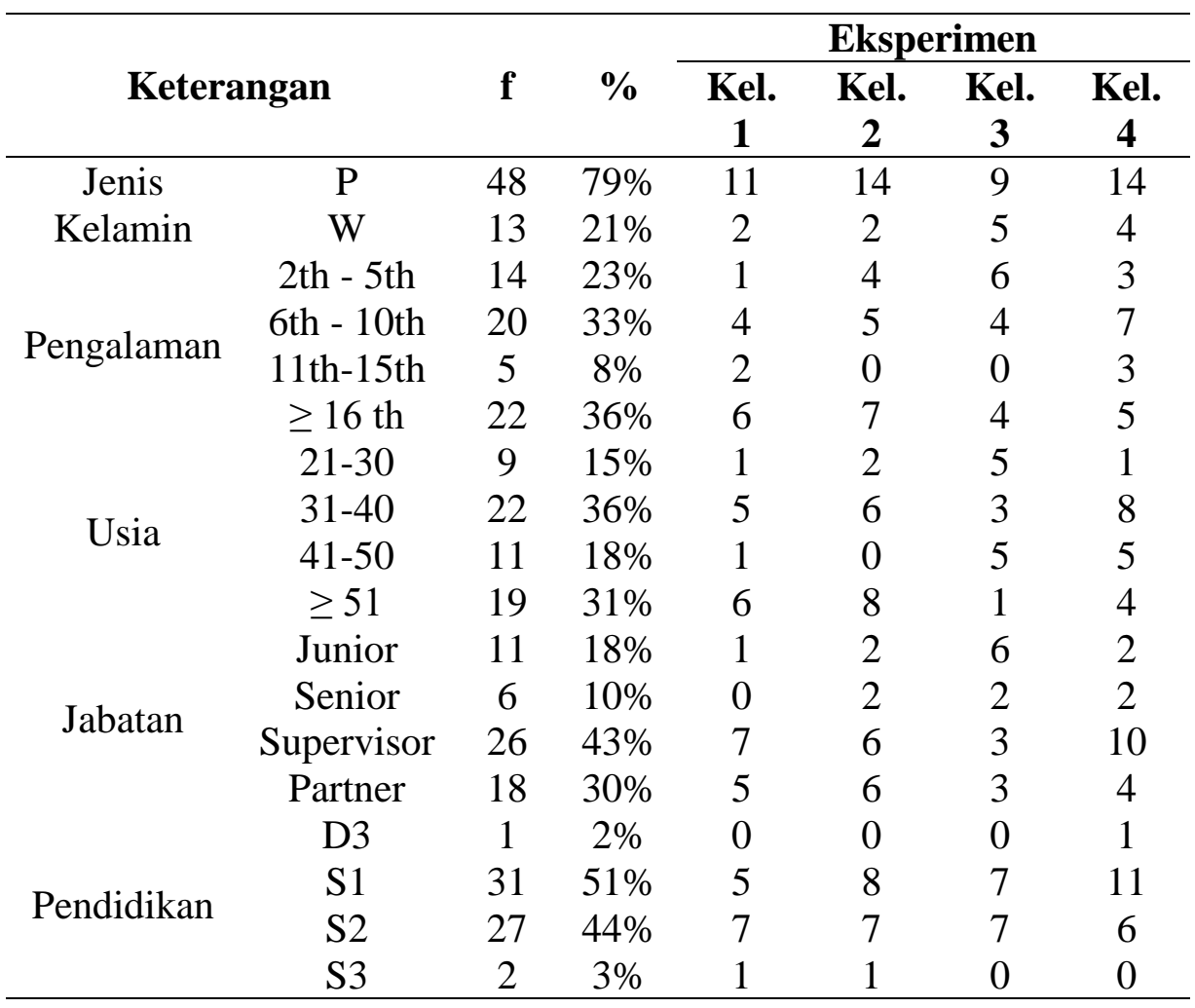

Sumber : Data Primer 2016

Jabatan partisipan didominasi oleh supervisor dan partner sehingga hal ini memenuhi syarat kriteria partisipan yaitu pernah melakukan supervisi terhadap auditor junior. Jumlah auditor junior sebanyak 11 orang (18\%), auditor senior sebanyak 6 orang $(10 \%)$, auditor supervisor sebanyak 26 orang $(43 \%)$ dan auditor partner sebanyak 18 orang (30\%). Berdasarkan jenjang pendidikan didominasi oleh $\mathrm{S} 1$ dan $\mathrm{S} 2$, dengan rincian D3 sebanyak 1 orang (2\%), S1 sebanyaj 31 orang (51\%), S2 sebanyak
27 orang (44\%) dan S3 sebanyak 2 orang $(3 \%)$.

Data demografi tersebut menggambarkan bahwa rata-rata auditor yang berpartisipasi dalam penelitian ini adalah auditor yang telah memiliki pengalaman melakukan supervisi. Dengan demikian partisipan dalam penelitian ini dianggap cukup kuat untuk memberikan gambaran terhadap kuesioner dan kasus yang telah diberikan dalam penelitian ini. Proses eksperimen dilaksanakan sesuai 
dengan prosedur eksperimen. Proporsi yang sama untuk setiap kelompok diharapkan mempunyai varians yang homogen, dan mendukung pengujian asumsi hipotesis.

\section{Pengujian Hipotesis}

Statistik Deskriptif eksperimen pertama, pada tabel 4 secara absolut menunjukkan bahwa terdapat perbedaan evaluasi penilaian kinerja antara auditor skeptis yang menemukan salah saji dengan auditor skeptis yang tidak menemukan salah saji. Total distribusi rata-rata auditor skeptis yang menemukan salah saji yaitu 2,6621 lebih tinggi dibandingkan dengan total distribusi rata-rata auditor skeptis yang tidak menemukan salah saji yaitu 1,7562.

Tabel 4

Statistik Deskriptif Eksperimen Pertama

\begin{tabular}{|c|c|c|c|}
\hline \multirow{2}{*}{$\begin{array}{c}\text { Skeptisme } \\
\text { Auditor }\end{array}$} & \multicolumn{2}{|c|}{ Skor Nilai } & \multirow{2}{*}{ Total } \\
\hline & Tinggi & Rendah & \\
\hline \multirow[t]{5}{*}{ Salah Saji } & Grup 1: & Grup 2: & \\
\hline & Mean $=3,3733$ & Mean $=1,9000$ & Mean $=2,6621$ \\
\hline & Std. Deviation $=$ & Std. Deviation $=$ & Std. Deviation $=$ \\
\hline & 0,58489 & 0.59226 & 0,94620 \\
\hline & $\mathrm{N}=15$ & $\mathrm{~N}=14$ & $\mathrm{~N}=29$ \\
\hline Tidak Salah & Grup 3: & Grup 4: & \\
\hline \multirow[t]{4}{*}{ Saji } & Mean $=2,7312$ & Mean $=0,7812$ & Mean $=1,7562$ \\
\hline & Std. Deviation $=$ & Std. Deviation $=$ & Std. Deviation $=$ \\
\hline & 0,78885 & 0,63793 & 1.21627 \\
\hline & $\mathrm{N}=16$ & $\mathrm{~N}=16$ & $\mathrm{~N}=32$ \\
\hline \multirow[t]{4}{*}{ Total } & Mean $=3,0419$ & Mean $=1,3033$ & Mean = 2,1869 \\
\hline & Std. Deviation $=$ & Std. Deviation $=$ & Std. Deviation $=$ \\
\hline & 0,75973 & 0,83066 & 1,17905 \\
\hline & $\mathrm{N}=31$ & $\mathrm{~N}=30$ & $\mathrm{~N}=61$ \\
\hline
\end{tabular}

Sumber : Data Primer 2016

Hasil uji One Ways ANOVA untuk menguji hubungan antara satu variabel dependen evaluasi kinerja dengan satu independen skeptisme auditor. Hasil One
Ways ANOVA dapat dilihat pada output spss pada tabel 5. 


\section{Tabel 5}

\section{Hasil One Ways ANOVA}

Dependent Variable: Performance

$\begin{array}{lrrrrr}\text { Source } & \begin{array}{l}\text { Type III } \\ \text { Sum of } \\ \text { Squares }\end{array} & \text { df } & \begin{array}{l}\text { Mean } \\ \text { Square }\end{array} & \text { F } & \text { Sig. } \\ \text { Corrected } & 58.621^{\mathrm{a}} & 3 & 19.540 & 44.933 & .000 \\ \text { odel } & 293.395 & 1 & 293.395 & 674.660 & .000 \\ \text { ercept } & 58.621 & 3 & 19.540 & 44.933 & .000 \\ \text { eptisme } & 24.788 & 57 & .435 & & \\ \text { or } & 375.140 & 61 & & & \\ \text { tal } & 83.410 & 60 & & & \end{array}$

R Squared $=.703$ (Adjusted R Squared $=.687$ )

Sumber : Data Primer 2016

Hasil uji Anova menunjukan bahwa terdapat pengaruh langsung antara variabel independen skeptisme. Hasilnya probabilitas (Sig.) adalah $0,000<0,05$ maka $H_{1}$ diterima yang artinya terdapat perbedaan penilaian kinerja antara skeptisme auditor yang menemukan salah saji dan skeptisme auditor yang tidak menemukan salah saji. Evaluasi penilaian kinerja auditor yang menemukan salah saji lebih tinggi daripada auditor yang tidak menemukan salah saji. Hal tersebut dapat dilihat pada tabel 4.3, nilai total mean grup 1 dan 2 sebesar 2,6621 lebih tinggi dari nilai total mean grup 3 dan 4 sebesar 1,7562.

\section{Statistik Deskriptif eksperimen} kedua, pada tabel 6 secara absolut menunjukkan bahwa terdapat perbedaan evaluasi penilaian kinerja antara auditor skeptis yang melakukan konsultasi dengan auditor skeptis yang tidak melakukan konsultasi. Hasil terlihat bahwa total distribusi rata-rata auditor skeptis yang melakukan konsultasi yaitu 2,4370 lebih tinggi dibandingkan dengan total distribusi rata-rata auditor skeptis yang tidak melakukan konsultasi yaitu 1,9882 


\section{Tabel 6}

\section{Statistik Deskriptif Eksperimen Kedua}

\begin{tabular}{|c|c|c|c|}
\hline \multirow{2}{*}{$\begin{array}{c}\text { Skeptisme } \\
\text { Auditor }\end{array}$} & \multicolumn{2}{|c|}{ Judgment Auditor } & \multirow{2}{*}{ Total } \\
\hline & Konsultasi & Tidak Konsultasi & \\
\hline \multirow[t]{5}{*}{ Salah Saji } & Grup 1: & Grup 2: & \\
\hline & Mean $=2,7846$ & Mean $=2,5625$ & Mean $=2,6621$ \\
\hline & Std. Deviation $=$ & Std. Deviation $=$ & Std. Deviation $=$ \\
\hline & 0,88774 & 1,00855 & 0,94620 \\
\hline & $\mathrm{N}=13$ & $\mathrm{~N}=16$ & $\mathrm{~N}=29$ \\
\hline Tidak Salah & Grup 3: & Grup 4: & \\
\hline \multirow[t]{4}{*}{ Saji } & Mean $=2,1143$ & Mean $=1,4778$ & Mean $=1,7562$ \\
\hline & Std. Deviation $=$ & Std. Deviation $=$ & Std. Deviation $=$ \\
\hline & 1,23466 & 1.15939 & 1,21627 \\
\hline & $\mathrm{N}=14$ & $\mathrm{~N}=18$ & $\mathrm{~N}=32$ \\
\hline \multirow[t]{4}{*}{ Total } & Mean $=2,4370$ & Mean $=1,9882$ & Mean = 2,1869 \\
\hline & Std. Deviation $=$ & Std. Deviation $=$ & Std. Deviation $=$ \\
\hline & 1,11464 & 1,20699 & 1,17905 \\
\hline & $\mathrm{N}=27$ & $\mathrm{~N}=34$ & $\mathrm{~N}=61$ \\
\hline
\end{tabular}

Sumber : Data Primer 2016

Hasil output analisis varian desain faktorial yang dapat digunakan untuk membuktikan hipotesis kedua. Tabel 7 ditampilkan hasil Tests of Between-Subjects
Effects untuk membandingkan antar kelompok/perlakuan.

Tabel 7

ANOVA Tests of Between-Subjects Effects

Dependent Variable: Performance

\begin{tabular}{|c|c|c|c|c|c|}
\hline Source & $\begin{array}{l}\text { Type III } \\
\text { Sum of } \\
\text { Squares }\end{array}$ & df & $\begin{array}{c}\text { Mean } \\
\text { Square }\end{array}$ & $\mathbf{F}$ & Sig. \\
\hline Corrected Model & $16.027^{\mathrm{a}}$ & 3 & 5.342 & 4.519 & .007 \\
\hline Intercept & 299.950 & 1 & 299.950 & 253.732 & .000 \\
\hline Skeptisme * & .000 & 0 & & & \\
\hline Judgment & & & & & \\
\hline Skeptisme & .000 & 0 & . & & . \\
\hline Judgment & 16.027 & 3 & 5.342 & 4.519 & .007 \\
\hline Error & 67.383 & 57 & 1.182 & & \\
\hline Total & 375.140 & 61 & & & \\
\hline Corrected Total & 83.410 & 60 & & & \\
\hline
\end{tabular}

R Squared $=.192$ (Adjusted R Squared $=.150$ )

Sumber : Data Primer 2016 
Hasil uji Anova menunjukan bahwa terdapat pengaruh langsung antara variabel independen skeptisme dan judgment. Judgment memberikan nilai F sebesar 4.519 dengan tingkat signifikan pada 0.05 , hal ini berarti bahwa terdapat perbedaan penilaian kinerja antara auditor yang melakukan konsultasi dan tidak melakukan konsultasi. Hasilnya probabilitas (Sig.) adalah 0,007 < 0,05 maka $\mathrm{H}_{2}$ diterima yang artinya atasan uditor yang tidak terkena outcome effect akan menilai kinerja auditor yang melakukan konsultasi, berbeda secara signifikan dengan kinerja auditor yang tidak melakukan konsultasi. Evaluasi penilaian kinerja auditor yang melakukan konsultasi lebih tinggi daripada auditor yang tidak melakukan konsultasi. Hal tersebut dapat dilihat pada tabel 4.5 , nilai total mean grup 1 dan 3 sebesar 2,4370 lebih tinggi dari nilai total mean grup 2 dan 4 sebesar 1,9882.

\section{Pembahasan}

Pengaruh Skeptisme Profesional Auditor Junior terhadap Evaluasi Kinerja oleh Auditor Senior

Hasil uji ANOVA sebagaimana yang disajikan pada tabel 5 menunjukkan bahwa $\mathrm{H}_{1}$ diterima sehingga dapat dinyatakan bahwa terdapat perbedaan penilaian kinerja antara skeptisme auditor yang menemukan salah saji dan skeptisme auditor yang tidak menemukan salah saji. Hasil mean pada tabel 4 juga menunjukkan bahwa grup skeptisme menemukan salah saji memiliki rata-rata mean lebih tinggi daripada grup skeptisme tidak menemukan salah saji. Sehingga dapat ditarik kesimpulan bahwa penilian kinerja auditor skeptis yang menemukan salah saji jauh lebih tinggi daripada auditor skeptis yang tidak menemukan salah saji.

Hasil ini konsisten dengan hasil penelitian Brazel (2015) yang menunjukkan bahwa Evaluasi kinerja oleh atasan kepada bawahan secara keseluruhan dipengaruhi oleh outcome. Sikap skeptis menjadi kurang menguntungkan ketika auditor tidak dapat mengidentifikasi salah saji. Hasil ini juga sejalan dengan penelitian Jones dan Chen (2005) yaitu evaluator akan menilai kinerja jauh lebih baik ketika audit yang over budget mendapat temuan yang signifikan. Akan tetapi ketika audit yang over budget tidak mendapatkan temuan signifikan maka ada kecenderungan untuk mengganti auditor lain di masa yang akan datang.

Penelitian ini juga sesuai dengan penelitian Lipe (1993) yaitu investigasi dipandang lebih menguntungkan ketika masalah ditemukan dalam sistem. Serta dalam penelitian Tan dan Lipe (1997) 
menyebutkan hasil suatu keputusan disebut sebagai outcome, hasil penelitian adalah bahwa ketika outcome baik evaluasi secara signifikan lebih tinggi daripada outcome yang buruk. Selain itu, penelitian yang serupa juga dilakukan oleh Brown dan Salomon (1987) dalam konteks evaluasi keputusan capital budget yang dipengaruhi oleh informasi outcome. Penelitian tersebut menguatkan pendapat bahwa bagaimanapun outcome mungkin menjadi masukan yang valid untuk penilaian kualitas keputusan. Hal tersebut dapat dijelaskan bahwa ketika proses keputusan yang tidak dapat diamati oleh evaluator, maka outcome dapat berfungsi sebagai isyarat yang digunakan oleh oleh evaluator sebagai dasar untuk menilai kinerja. Evaluasi keputusan terpengaruh oleh outcome, jika misalnya ada anggapan bahwa evaluator dianggap tidak tepat mepertimbangkan informasi yang relevan yang masih ada.

Hasil penelitian ini sesuai dengan konsep framing dalam teori prospek yang didaptasi dalam penelitian Lipe (1993), Jones dan Chen (2005) dan Brazel (2015). Penelitian menyebutkan bahwa dampak framing pada persepsi evaluator dibingkai biaya (cost) atau kerugian (lost). Dalam penelitian ini framing diadaptasi dari penelitian Brazel (2015), yaitu sikap skeptisme yang menyebabkan prosedur tambahan dibingkai sebagai "normal cost" jika menemukan salah saji. Sedangkan sikap skeptisme yang menyebabkan prosedur tambahan dibingkai sebagai "loss time" jika tidak menemukan salah saji. Evaluator dengan cost frame memberikan penilaian kinerja lebih tinggi dibandingkan dengan loss frame. Jika dikaitkan dengan pada tabel 4.3 juga menunjukkan bahwa grup skeptisme menemukan salah saji memiliki rata-rata mean lebih tinggi daripada grup skeptisme tidak menemukan salah saji. Sehingga dapat diambil kesimpulan bahwa evaluator dengan cost frame akan menilai kinerja auditor lebih tinggi ketika sikap skeptisme profesional menemukan salah saji.

\section{Pengaruh Hasil Temuan Auditor Junior} dan Konsultasi terhadap Evaluasi Kinerja oleh Auditor Senior

Hasil uji ANOVA pada tabel 7, menunjukkan bahwa $\mathbf{H}_{2}$ diterima artinya bahwa atasan yang tidak terkena outcome effect akan menilai kinerja auditor yang melakukan konsultasi, berbeda secara signifikan dengan auditor yang tidak melakukan konsultasi. Hasil mean pada tabel 6 juga menunjukan bahwa grup auditor skeptis yang melakukan konsultasi memiliki 
nilai rata-rata lebih tinggi daripada grup auditor skeptis yang tidak melakukan konsultasi. Sehingga dapat ditarik kesimpulan bahwa penilaian kinerja auditor skeptis yang melakukan konsultasi jauh lebih tinggi daripada auditor skeptis yang tidak melakukan konsultasi. Penelitian ini telah menguatkan pendapat bahwa konsultasi dapat mengurangi outcome effect.

Hasil ini juga sesuai dengan penelitian Brown dan Solomon (1987) yang menyebutkan bahwa konsultasi dengan atasan dapat mengurangi outcome effect dengan mengurangi asimetri informasi. Hasil penelitian Mertins (2013) juga menyebutkan bahwa outcome effect berkurang (meski tidak dihilangkan) ketika evaluator mengamati proses pengambilan keputusan. Evaluator atau atasan auditor yang terlibat dalam proses pengambilan keputusan seharusnya kurang terpengaruh oleh informasi outcome. Hal yang mendasari pernyataan tersebut yaitu pertama: evaluator yang terlibat dalam proses pengambilan keputusan, evaluator harus berada dalam posisi yang lebih baik daripada evaluator yang tidak terlibat. Posisi yang lebih baik ini menyangkut pemahamaman tingkat ketidakpastian yang dihadapi auditor junior ketika membuat keputusan mengenai tindakan yang akan diambil (Brown, 1987). Kedua, ketika evalutor menyarankan kepada auditor junior untuk mengambil tindakan tertentu dan tindakan yang dianjurkan diambil, maka evaluator harus menyadari bahwa posisinya mengetahui secara bersama "knew all along", artinya bahwa evaluator mengetahui secara seksama bagaimana keputusan harus diambil diantara alternatif lain (Brown, 1987).

Glover et al. (2014) juga menunjukkan bahwa menciptakan budaya konsultasi dapat meningkatkan aplikasi yang sesuai skeptisme. Glover (2014) membahas ancaman terhadap skeptisme profesional pada perikatan audit dapat diatasi dengan membangun sebuah budaya konsultasi di lingkungan kerja Kantor Akuntan Publik (KAP). Auditor diharapkan membangun komunikasi dengan atasannya ketika terjadi tekanan (misalnya: deadline), komunikasi tersebut harus disampaikan secara baik kepada atasannya. Aplikasi yang sesuai skeptisme profesional hanya mungkin bila auditor memiliki keahlian audit yang diperlukan dan tidak hanya memahami masalah, tetapi secara proaktif membingkai ulang masalah (Glover, 2014). Budaya KAP harus mendukung auditor dalam memperoleh keahlian yang diperlukan untuk melaksanakan profesional skeptisme, yaitu seperti konsultasi yang memadai dalam beberapa keadaan diperlukan. 
Penelitian ini sesuai dengan teori eskalasi komitmen (Staw 1976) yang menyebutkan jika auditor terlibat dalam tindakan yang disepakati oleh atasan, maka atasan memiliki motivasi untuk memandang perilaku skeptis lebih menguntungkan (Brown dan Salomo 1993). Teori eskalasi komitmen menyebutkan ketika perilaku sesorang menyebabkan konsekuensi negatif, hal yang sering terjadi adalah individu tersebut tidak mengubah perilakunya untuk mendistorsi konsekuansi negatif menjadi lebih positif. Fenomena yang mendasari perilaku ini dikatakan sebagai proses pembenaran diri dimana individu berusaha untuk merasionalisasi perilaku mereka atau psikologis membela diri terhadap konsekuensi yang merugikan (Bazerman dalam Kadous, 2002).

Sistem Pengendalian Mutu (SPM) No. 1 Tahun 2013 paragraf 34 dan paragraf A29A33, menyebutkan bahwa salah satu unsur pengendalian mutu dalam pelaksanaan perikatan yaitu konsultasi. Nelson (2009) juga menyebutkan bahwa sesi brainstorming kecurangan merupakan salah satu pengaturan konsultasi yang dapat meningkatkan skeptisme profesional. Hasil penelitian ini membuktikan bahwa efek konsultasi menyebabkan atasan auditor akan memandang perilaku skeptis bawahan tidak hanya berdasarkan hasil temuan audit saja, tetapi lebih menilai sikap skeptisme profesional yang dimiliki bawahannya.

\section{KESIMPULAN DAN SARAN}

\section{Kesimpulan}

Penelitian ini menguatkan teori tentang outcome effect dalam konteks mengevalusi kinerja auditor pada perikatan audit. Outcome dari perilaku skeptis dalam penelitian ini adalah ada atau tidaknya temuan salah saji. Beberapa penelitian tentang outcome dilakukan oleh Lipe (1993), Tan dan Lipe (1997), Jones dan Chen (2005) dan Brazel (2015). Oleh sebab itu penelitian ini dilakukan pengujian empiris di indonesia.

Penelitian ini melihat pengaruh skeptisme dengan beberapa tingkat level yang diberikan serta adanya pengaruh dari konsultasi yang dikondisikan dalam beberapa level. Evaluasi kinerja auditor yang dibahas dalam penelitian ini adalah bagimana skeptisme dan konsultasi mempengaruhi evaluasi kinerja auditor.

Hasil temuan dalam penelitian ini, pertama, terdapat perbedaan penilaian kinerja antara skeptisme auditor yang menemukan salah saji dan skeptisme auditor yang tidak menemukan salah saji, dimana penilian kinerja auditor skeptis yang menemukan salah saji jauh lebih tinggi daripada auditor 
skeptis yang tidak menemukan salah saji. Kedua, terdapat perbedaan penilaian kinerja antara skeptisme profesional auditor yang konsultasi dan skeptisme auditor yang tidak konsultasi dengan atasanya. Hal tersebut membuktikan bahwa variabel konsultasi dapat mengurangi outcome effect sehingga evaluator tidak terkena efek tersebut. Hal ini dibuktikan dari hasil evaluasi auditor skeptis yang menemukan salah saji dan tidak melakukan konsultasi dengan atasannya, nilai mean tidak berbeda secara signifikan dengan dari auditor yang tidak menemukan salah saji dan melakukan konsultasi dengan atasannnya. Perbedaan yang tidak signifikan bisa disebabkan adanya respon positif dari atasan auditor ketika mereka dilibatkan dalam pengambilan keputusan, meskipun hasilnya memberikan konsekuansi negatif. Jika keputusan diambil secara bersama lewat konsultasi antara atasan auditor dengan auditor junior, maka atasan auditor secara seksama mengetahui tingkat ketidakpastian yang dihadapi auditor junior ketika membuat keputusan tersebut. Oleh sebab itu, skeptisme auditor junior yang konsultasi dengan atasannya akan dinilai lebih baik daripada auditor yang tidak melakukan konsultasi.

\section{Keterbatasan Penelitian}

Penelitian ini menggunakan metode eksperimen, yang memiliki validitas internal lebih tinggi dari pada validitas eksternal. Faktor-faktor yang mengancam validitas eksternal eksperimen berasal dari interaksi antar manipulasi dengan variabel-variabel lainnya. Eksperimen tak akan bisa mencerminkan kondisi dunia nyata secara pasti karena laboratorium tersebut hanya merupakan tiruan dari realita. Oleh sebab itu eksperimen tidak dapat digunakan untuk membuat estimasi tentang populasi. Keterbatasan berikutnya berada pada instrumen penelitain ini dengan teknik pengumpulan data dengan kuesioner. Pada kuesioner perlu dipahami kebenaran sikap partisipan dalam menanggapi pertanyaan penelitian, karena jika menemukan subyek positif maka akan berkeinginan untuk menyukseskan penelitian dengan menebak arah penelitian supaya hipotesis dapat didukung, atau subyek negatif yang berniat untuk menggagalkan penelitian atau subyek yang kurang sreg dengan penelitian.

Partisipan dalam eksperimen ini memiliki perbedaan ukuran kantor akuntan publik dan perbedaan tingkat pendidikan. Hal ini kemungkinan juga menyebabkan perbedaan tingkat skeptisme profesionalnya. Selain itu sebagian besar auditor yang diamati dalam penelitian ini berasal dari kantor akuntan publik kecil dan menengah, sehingga hasil penelitian ini kemungkinan 
kurang representatif apabila digunakan untuk auditor dari kantor akuntan publik besar.

\section{Saran}

Saran untuk penelitian selanjutnya berkenaan dengan penelitian ini adalah dengan melakukan penelitian yang langsung terhadap lingkungan auditor tersebut yaitu dengan menggunakan eksperimen lapangan. Dalam sebuah eksperimen lapangan, kegiatan manipulasi variabel independen tersebut dilakukan dalam situasi nyata sehari-hari sehingga memiliki validitas eksternal lebih tinggi dan dapat digeralisasi. Eksperimen lapangan mempunyai keunggulan yang cocok digunakan untuk menyelesaikan permasalahan-permasalahan praktis. Hal ini karena situasi penelitian yang melatarbelakangi besifat realitis. Saran lebih lanjut untuk menguji variabel konsultasi menjadi bentuk konsultasi yang lebih terstruktur dan terarah seperti brainstorming.

\section{DAFTAR PUSTAKA}

Baron, J., and J. Hershey. 1988. Outcome bias in decision evaluation. Journal of Personality and Social Psychology, 54(4): 569-579.

Bell, T.B., M. Peecher, dan I. Solomon. 2005. The 21st Century PublicCompany Audit: Conceptual Elements of KPMG's Global Audit
Methodology. Montvale, New Jersey: KPMG

Brazel, J. F., K. L. Jones, and M. F. Zimbelman. 2009. "Using nonfinancial measures to assess fraud risk". Journal of Accounting Research, 47 (December): 11351166.

Brazel, J. F., K. L. Jones, and D. Prawitt. 2014. "Auditors' reactions to inconsistencies between financial and nonfinancial measures: The interactive effects of fraud risk assessment and a decision prompt". Behavioral Research in Accounting, 26 (1): 131-156.

Brazel, J.F., S. B. Jackson, T. J. Schaefer and B. W. Stewart. 2015. "The Outcome Effect dan Profesional Skepticism". Working Paper. Poole College of Management

Brown, C. E., and I. Solomon. 1993. "An experimental investigation of explanations for outcome effects on appraisals of capital-budgeting decisions". Contemporary Accounting Research, 10 (1): 83-111.

Brown, C. E., and I. Solomon. 1997. "Effects of Outcome Information on Evaluations of Managerial Decisions". The Accounting Review, Vol. LXII. No.3

Carpenter, T.D., dan J.L. Reimers. 2013. "Professional Skepticism: The Effects of a Partner's Influence and the Level of Fraud Indicators on Auditors' Fraud Judgments and Actions". Behavioral Research in Accounting. Vol. 25 No.2. pp 45-69. American Accounting Association 
Clarkson, Peter M, Craig Emby, dan Vanessa W-S Watt. September 2002. Debiasing the Outcome Effect:The Role of Instructionsin an Audit Litigation Setting. Auditing: A Journal of Practice \& Theory Vol. 21, No. 2

Cooper D. R \& Schindler, P. 2011. Business Research Method. Eleventh Edition, New York, NY: McGraw Hill

Dechow, P.M., Weili GE., C.R. Larson, R.G, Sloan. 2011. "Predicting Material Accounting Misstatements". Contemporary Accounting Research. Vol. 28 No. 1. pp: 17-82.

Frederickson, J.R., Peffer, S.A. and Pratt, J. (1999), "Performance evaluation judgments: effects of prior experience under different performance evaluation schemes and feedback frequencies", Journal of Accounting Research, Vol. 37 No. 1, pp. 1-15.

Glover, S. M., D. F. Prawitt. 2014. "Enhancing auditor professional skepticism: The professional skepticism continuum". Current Issues in Auditing, 8 (2): 1-10.

Ghosh, D., and R. Lusch. 2000. Outcome effect, controllability, and performance evaluation on managers: Some field evidence from multioutlet businesses. Accounting, Organizations and Society, 25: 411425

Hershey, J. C., \& Baron, J. 1995. REJOINDER Judgment by outcomes: When is it warranted? Organizational Behavior and Human Decision Processes, 62(1), 127
Hurtt, R. K., H. Brown-Liburd, C. E. Early, and G. Krishnamoorthy. 2013. "Research on auditor professional skepticism: Literature synthesis and opportunities for future research. Auditing: A Journal of Practice \& Theory, 32 (Supplement): 45-97.

Hunt, S.C.1995, "A review and synthesis of research in performance evaluation in public accounting", Journal of Accounting Literature, Vol. 14, pp. 107-39.

International Auditing and Assurance Standards Boards. (IAASB). 2004. International Standard on Auditing. New York: IFAC.

IFAC. 2007. Handbook of International Auditing, Assurance, and Ethics Pronouncements. New York.

Jones, K. T., \& Chen, C. C. 2005. "The effect of audit outcomes on evaluators' perceptions". Managerial Auditing Journal, 20(1), 5-18.

Kadous, Kathryn. 2000. The Effects of Audit Quality and Consequence Severity on Juror Evaluations of Auditor Responsibility for Plaintiff Losses. Vol. 75 No. 3. pp: 327-341. The Accounting Review.

Kadous, K. 2001. Improving jurors' evaluations of auditors in negligence cases. Contemporary Accounting Research 18 (3): 425-49.

Kadous, K., and A. Magro. 2001. The effects of exposure to practice risk on taxprofessionals'judgements and recommendations. Contemporary Accounting Research 18 (3): 451-75. 
Kadous, Kathryn 2002, The Role Mental Representation in Organizational Escalation of Commitment, http://www.emeraldinsight.com, Diakses tanggal 4 November 2009

KPMG LLP (KPMG). 2012. Comment letter on the board's concept release on auditor independence and audit firm rotation. Delivered at PCAOB public meeting. March 21. Available at: http://pcaobus.org/Rules/Rulemaking/ Docket037/ps_veihmeyer.pdf.

Lipe, M.G. 1993. "Analyzing the variance investigation decision: the effects of outcomes, mental accounting, and framing", The Accounting Review, Vol. 68 No. 4, pp. 748-64.

Mertins, L., D. Salbador, and J. Long. 2013. "The Outcome Effect - A Review and Implications for Future Research". Journal of Accounting Literature, 31 (1): 2-30.

Nelson, M. 2009. "A model and literature review of professional skepticism in auditing". Auditing: A Journal of Practice \& Theory, 28 (2): 1-34

Noviyanti, Suzy (March 2015). The Role of "Tone at The Top" and Knowledge of Fraud on Auditors' Professional Skeptical Behavior". Pages 53-72, Vol. 11, No. 1. Contemporary Management Research

Public Company Accounting Oversight Board (PCAOB).2008. Report on the PCAOB's 2004, 2005, 2006, and 2007 inspections of domestic annually inspected firms. Washington, D.C.
Reason, T. 2010. Auditing your auditor. CFO.com. April 2010. Available at: http://www.cfo.com/printable/article. cfm/14485723.

Sekaran, U., 2013. Research Methods for Business: A Skill Building Approach. Fourth Edition. John Willey\&Sons., Inc., New York.

Shaub, M. K. and J. E. Lawrence. 2002. "A taxonomy of auditors' professional skepticism'. Research on Accounting Ethics 8: 167-194.

Staw, B. M. 1976. Knee-deep in the Big Muddy: A study of escalating commitment to a chosen course of action. Organizational Behavior and Human Performance, 16: 27-44.

Tan, H. T., and M. G. Lipe. 1997. "Outcome effects: The impact of decision process and outcome controllability". Journal of Behavioral Decision Making, 10: 315-325.

Thaler, Richard H. 2008. Mental Accounting and Consumer Choice. Vol. 27, No. 1, January-February 2008, pp. 15-25. Marketing Science.

Tversky, A. and Kahneman, D. 1979. "Prospect Theory: An Analysis of Decision under Risk". Econometrica, Vol. 47, No. 2. (Mar., 1979), pp. 263292.

Tversky, A. and Kahneman, D. 1986. "Rational Choice and the Framing of Decisions". The Journal of Business, Vol. 59, No. 4, Part 2: The Behavioral Foundations of Economic Theory. pp. S251-S278. 
Wright, A. (1980), "Performance appraisal of staff auditors", The CPA Journal, Vol. 50, November, pp. 37-43. 